They divide the period into three parts covering roughly 1871-1914, the inter-war years and the 1950s, though by far the most lengthy and vigorous discussion is that pertaining to the first period. Considerable attention is paid to the controversial check to income and productivity in Britain at the end of the nineteenth century and some familiar explanations are debated in detail. Economic historians, especially those with a statistical slant, will find some rich pickings in this volume and no student of the modern period can afford to ignore it. There is much, too, that will be of interest to the informed general reader, though the non-specialist may find the text tough going.

It might seem ungracious to offer criticism after such a magnificent effort. But a careful reading of the work (in fact I read it twice) and a spot check of the calculations did raise one or two awkward points or queries. First, it is difficult to link some of the series across the periods because of differences in coverage. Here, of course, the main problem is availability of long-term comparative data. Second, it is not always clear exactly to which set of figures the authors are referring, so that it is often necessary to check back carefully. No doubt it is tedious to have to keep defining the coverage of series, but in a work of this type it is essential to do so. Third, it is not always immediately clear from which series some of the calculations in the tables of the text have been derived. A little more explanatory information here and there would certainly help the reader. Finally, there are one or two of the inevitable proof-reading or printing errors, notably the figure for net domestic income per occupied person in 1938 (Appendix 3, U.K. Table, 1913, 1920-1938, column 5). Since this book will no doubt become a standard reference work for many years to come, there will be plenty of opportunity for minor revisions and corrections in later editions.

DEREK H. Aldocroft

\section{GUIDE TO FINDING OUT}

How to Find Out about the Chemical Industry By Russell Brown and G. A. Campbell. (The Commonwealth and International Library of Science, Technology, Engineering and Liberal Studies: Libraries and Technical Information Division.) Pp. xiii + 219. (Pergamon: Oxford, London and New York, 1969.) 35s board; 258 paper.

THIs is a new member of a series of "How to find out" books published by Pergamon. It follows the standard layout, that is to say it begins with a brief historical outline of the topic covered and gives a good deal of attention to careers and training before describing and listing the available reference books, handbooks, periodicals, abstracts and other types of literature; the various appropriate trade, professional, government and international organizations; research; and safety. There is overlap with C. R. Burman's earlier How to Find Out in Chemistry, but in spite of this the two are in some senses companion volumes and would both be required when knowledge of the basic chemistry behind the industry is needed, as it sometimes will be. The trade journals, handbooks and directories of chemical industry have lent themselves more readily to sub-division than have those of pure chemistry, which makes the new book seem, perhaps unjustifiably, to be more logically presented than the older one.

The criticisms which can be levelled against this hand. book are really faults of the series. The introductory matter is rather naïve in places, being obviously intended for the young people, totally ignorant of the chemical industry, for whom the immediately following sections containing career information and advice about training are designed. There is then a sudden jump to an appreciably higher level, the remaining chapters being more useful to people already working in the chemical industry or as information scientists in that industry-from this point onwards the book is a guide to sources of specialized information. The two parts do not accord well with each other, and the final chapter, on the computer in the chemical industry, seems out of place. In a few pages it attempts to answer the question "what is a computer ?", and then merely mentions that computers can be put to use for process control and that their application to the chemical industry offers further career opportunities. It is questionable if the introduction of small-scale reproductions of the pages of a few selected reference books as illustrations has any real value.

Taken primarily as a guide to sources of information, certainly its best part, this book provides a good outline introduction and includes all necessary secondary reference material to enable more detailed information to be found when required. There is evidence that the manuscript was completed rather a long time before publication. For example, there are later editions than those quoted of the Aslib Directory and Industrial Research in Britain, and in a few cases one would have expected more recent articles or books to have been chosen as representative. The information presented, however, is far from being as widely known as it ought to be, even amongst those who are working in the chemical industry, and this book could easily save its cost by a single use which might well give a busy person the very facts he needed.

WILFRed Ashworth

\section{NOTABLE SCIENTISTS}

\section{World Who's Who in Science}

A Biographical Dictionary of Notable Scientists from Antiquity to the Present. Edited by Allen G. Debus. (Marquis Biographical Library.) Pp. xvi+1855. (Marquis Who's Who: Chicago, 1968.) n.p.

A cOMPILER of a scientific "Who's Who" faces some formidable demarcation problems. He has to trace boundaries somewhere along the indistinct borderlands between science and philosophy, science and technology, science and social theory, science and medicine. Professor Allen G. Debus, editor of World Who's Who in Science, certainly cannot be accused of skimping his territory. Besides every type of natural and social scientist, his thirty thousand entries include a fair sprinkling of mavericks (Wilhelm Reich), mystics (Teilhard de Chardin), visionaries (Karl Marx), dupes (Trofim Lysenko), crusaders (Buckminster Fuller), and many more-all strangers to the usual scientist's dictionary.

The book lists "notable scientists from antiquity to the present", so that Aristotle, Pythagoras et al. find a place too. Debus's approach to earlier societies is tinetured with Marxism. He covers subjects no longer considered integral to science provided that "they were thought to be a legitimate path to truth in nature in earlier periods". Thus distinguished alchemists and astrologers are included.

This is an admirable approach, though, in making it, Debus has perhaps opened Pandora's box. If astrology, why not necromancy, soothsaying, yoga and the rest ? Still, it is all to the good that the young Turks of molecular biology and theoretical physics should find themselves listed alongside Renaissance scholastics and Arab metaphysicians. The quantum of achievement that the editor makes the entrance fee to his book seems to favour the Americas somewhat: there are some surprising omissions among contemporary European scientists. But future editions may rectify this.

So now the world of science has its "Who's Who". No doubt the personnel changes of subsequent editions will become a matter for intense scrutiny in the world's laboratories. The volume is solidly and satisfyingly made, as one would expect in a book from the publishers of Who's 